Volume 9, No.3, May - June 2020

International Journal of Advanced Trends in Computer Science and Engineering

Available Online at http://www.warse.org/IJATCSE/static/pdf/file/ijatcse36932020.pdf

https://doi.org/10.30534/ijatcse/2020/36932020

\title{
Utilizing Big Data Framework to Support Decision Making Process: Enterprise Architecture Approach
}

\author{
Yulyanty Chandra ${ }^{1}$, Renny Triana ${ }^{2}$, Gunawan Wang ${ }^{3}$, Nilo Legowo ${ }^{4}$ \\ 1,2,3 Information Systems Management Department, BINUS Graduate Program-Master of Information Systems \\ Management, Bina Nusantara University, Jakarta, Indonesia. \\ 1yulyanty.chandra@binus.ac.id; ${ }^{2}$ renny.triana@binus.ac.id; ${ }^{3}$ gwang@binus.edu; ${ }^{4}$ nlegowo@binus.edu
}

\begin{abstract}
A university is expected to continue to develop through various periods of change and innovation to remain at the forefront in the field of information technology, and always produce graduates who are ready to apply and have quality. A university's commitment to quality, has pushed to implement a quality management system to maintain the overall education program that has been built. With strategic planning and university business management processes, designing an Enterprise Architecture (EA) as an architectural basic for providing data for the analysis of university management conditions using big data technology and data analytics is the answer. So that information can support rapid decision-making process in business management. This study uses the Value Chain method to analyze business processes, and the Zachman Framework approach to detail the needs of enterprise architecture, with the highest goal of this research is to produce Enterprise Architecture design and management blueprints.
\end{abstract}

Key words: Enterprise Architecture Approach, Data, Zachman Framework, Value Chain, Support Decision Making Process.

\section{INTRODUCTION}

Each data has its own story to be known by others, because data is very important. By using technology, the process of collecting, managing, then data analysis can be optimized. Big data text analytics can help organizations find hidden knowledge and generate new knowledge from large amounts of structured and unstructured data [1]. The back-end in big data applications are engines can process unstructured data such as social media images, video, or internal application service applications or business partners. Structured data provided by conventional DBMS will be processed and combined with unstructured data. Processing results will be used in reports or stored in a data warehouse for later use in strategic analytical needs [2].
Because the information generated from these data is a key success factor that influences the leadership in making decisions, especially on the quality of those decisions. Data is displayed so that information can be received by others and can answer questions about how, where, the exact amount (descriptive-analytic) and what happened (diagnostic analytic). The big data analysis requires a massive database to collect all the information, hence Cloud computing becomes an alternate for accumulating the concerning information for a particular system [3].

At a university, prospective student data, school origin, regional origin, active students, student achievement, payment status, lecturer profile, departmental and lecturer performance achievements are needed by the leadership from the dashboard form and viewed in a strategic view. Data that is real-time, visualized well and can be accessed anywhere will greatly support the quality of decision making by the leadership. The purpose of this study is to create an enterprise architecture for universities in changing the business model with the existence of business intelligence and big data in supporting the quality of decision making.

\section{RESEARCH METHOD}

To assist in this research process, researchers used the Action Research methodology. Action Research Methodology is a way for individuals or groups to organize a situation that exists, so that they can learn all experiences and make these experiences can also be felt by others [4].

Action research in the traditional view is a research framework for problem solutions, where collaboration occurs between researchers and clients in reaching goals. As seen in the figure 1, the main concept of this action research consists of four components: (a) planning, (b) acting, (c) observing, and (d) reflecting. 


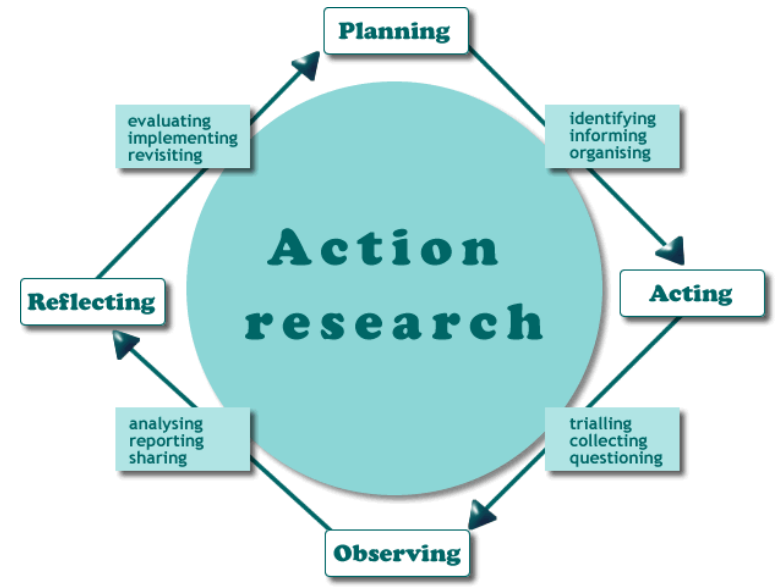

Figure 1: Action Research

Value Chain Analysis is also used to analyze the company's internal activities. In other words, by looking into internal activities, the analysis reveals where a company's competitive advantage or drawbacks are. Companies that compete through differentiation advantage will try to do activities better than competitors will. For the action research method, the researcher will combine the approach method with the Zachman Framework and Porter's Value Chain Model which was introduced by Michael Porter in 1985 in the figure 2.

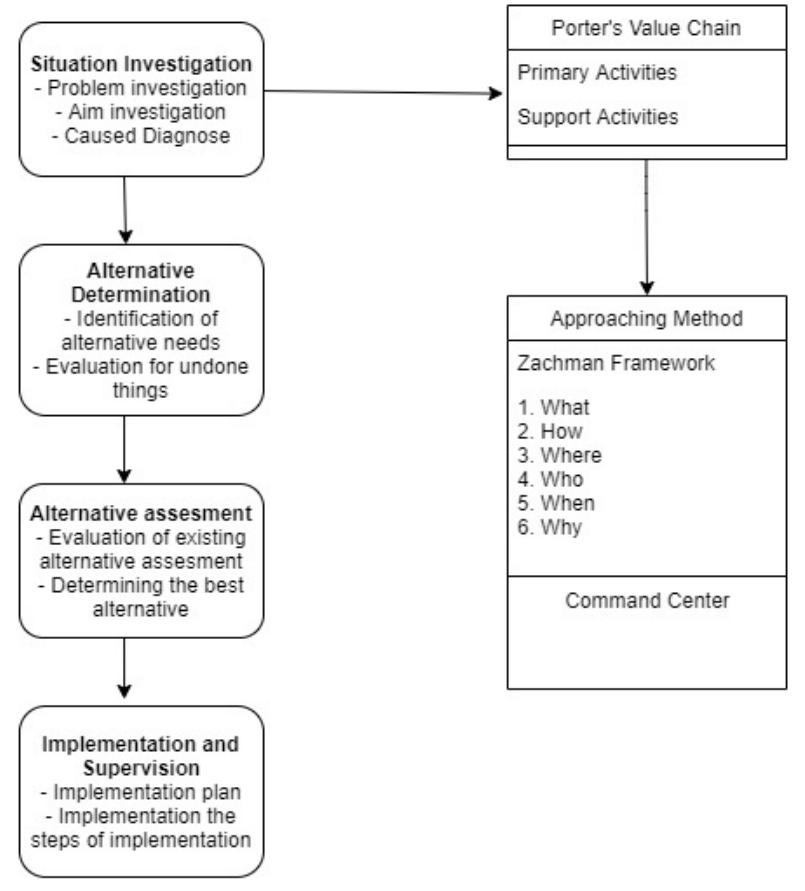

Figure 2: Research Flow

\section{THEORETICAL FRAMEWORK}

In this study, we use the architecture of the ISA Zachman Framework in the figure 3. John Zachman interpreted that Enterprise Architecture (EA) is a collection of total intersections between abstraction and perspective which is a collection of total descriptive representations that are relevant for describing a company: six-line [5].
For the Zachman Framework perspective which consists of Scope perspective, Enterprise Model, System Model and Technology Model is described in tabular form according to the Zachman Framework pattern [6].

Here are the columns of the Zachman Frameworks: (1) what is discussing the university data, (2) how is to discuss the processes that occur within the university, (3) where is to discuss to the main location for the business, (4) who is to discuss the human resources in university, (5) when discussing the definition of activities and the allocation of time use for activities carried out by the university, (6) why is discussing all the things the university wants to achieve.

ENTERPRISE ARCHITECTURE - A FRAMEWORK ${ }^{\mathrm{m}}$

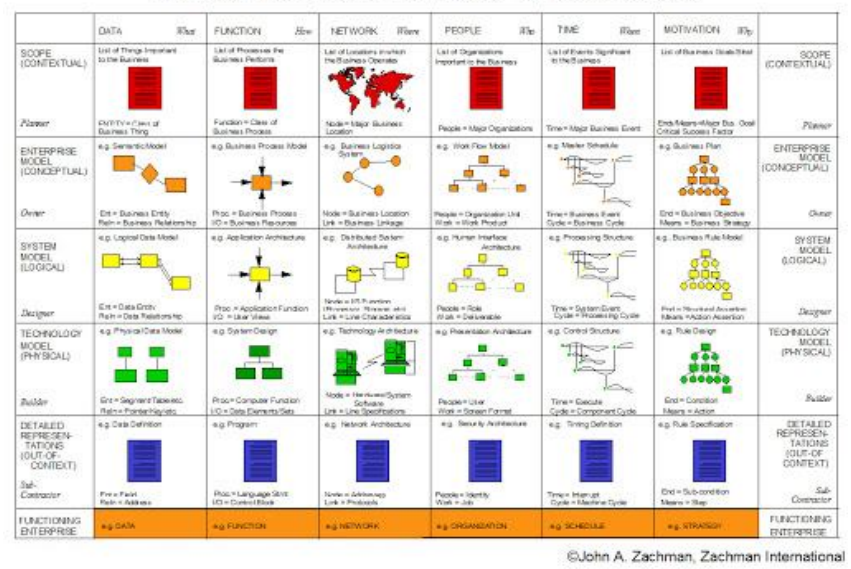

Figure 3: Zachman Framework

\section{RESULT AND DISCUSSION}

The action research method used in this study by combining the Zachman Framework approach and the Porter's Value Chain Model results is as follows.

\section{A. Planning}

Every month, units and departments send monthly reports and upload them to the portal that is provided by the university. From the information uploaded, it is collected into one report for the leadership. The information is used as a basis and is used in making strategic plans by the leadership, but the information reported can be said to be invalid because the numbers presented are not up to date, and if the leader wants to know what are the valid numbers, the unit and department must pull the data back and process it into information. So the question of how, where, the exact number (descriptive-analytic) and what happened (diagnostic analytic) is not yet available because there is no dashboard of real-time information.

The Porter's Value Chain Model result is:

- It can be identified that a dashboard is needed that can support the visualization of information.

- This strategy is to increase the analytics layer (descriptive and analytical Diagnose).

- So that all achievements can be seen and visualized 
from all dimensions and perspectives.

The result for Zachman Framework method is:

1) What

In this discussion will be discussed about the university important entities in it are:

a) Marketing, starting from the process of registering prospective students, entrance tests, students joining, and including the resignation of new students.

b) Academic, starting from the curriculum-making process, student registration, tuition payment, lecturer scheduling, lecturer honorarium payment, student development, graduate placement, lecturer and student publications.

2) How

The discussion in this discussion about the main processes that occur within the university, namely:

a) Data processed by units and majors.

b) Uploaded to the university portal in the form of reports.

c) Data is collected and made into reports for leaders.

d) Reports made also include issues that occur, solutions that will be done, including the proposed initiatives.

In Figure 4, the report device architecture contains several things such as data processing, translation, security, and delivery. In data processing, data comes from MySQL, SQL, ODBC, Oracle, Excel. After processing the data, the data will be presented with outputs like HTML, pdf, or Excel. For the business model, these processes will be incorporated through the OLAP Application system which will then be processed into information to be used as a reference for reporting to management.

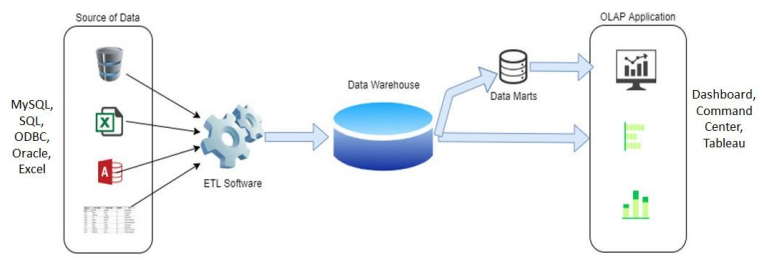

Figure 4: Architecture Reporting Tools

3) Where

This section discusses the location where this entity is inside the university. In this case, the university has more than one building, more than one campus, and is in various regions. In the business model section, we will discuss the network technology systems used between campuses mentioned above. To connect the network, the network used today is a fiber-optic network using the VPN (Virtual Private Network) method.
4) Who

This section discusses human resources who have an important role in universities, namely:
a) Marketing Manager
b) Academic Manager
c) Operational Manager
d) Student Advisory Manager
e) Alumni Manager
f) Research Manager

In the business model section, an outline of the company's organizational structure is explained. And in the Figure 5, an important part of the organization is explained. Data entered by related parties will be used and processed into all reports that will be displayed to the leadership.

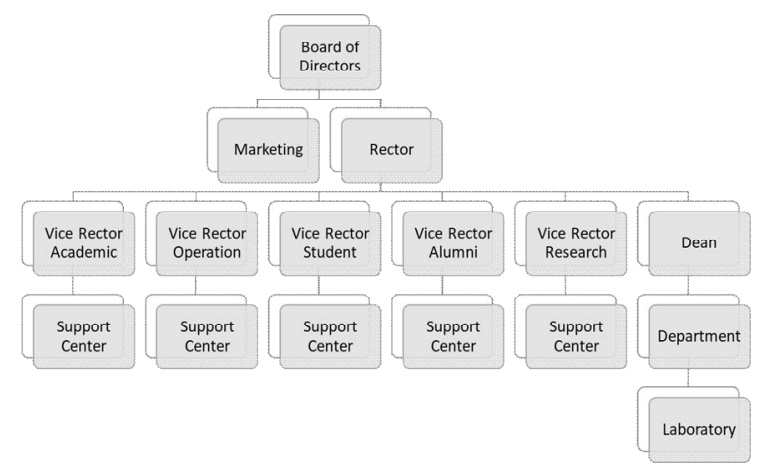

Figure 5: Organizational Structure

5) When

The main activities in preparing a dashboard are:

a) Providing the data access (OLTP - Online Transaction Processing).

b) Collect the data (ETL - Extract, Transform, and Load).

c) Save data (Warehouse Data).

d) Analyze the data (Reporting and OLAP - Online Analytical Processing).

In the business model will describe the design of the work plan from the analysis of user needs to implementation in the figure 6 below.

\begin{tabular}{|c|c|c|c|c|c|c|c|c|c|c|c|c|}
\hline \multirow[b]{2}{*}{ Activity } & \multicolumn{12}{|c|}{ waktas } \\
\hline & $\begin{array}{c}\text { Feb } \\
2019\end{array}$ & $\begin{array}{l}\text { Atar } \\
20115\end{array}$ & $\begin{array}{l}\text { Apr } \\
\text { XDis }\end{array}$ & $\begin{array}{l}\text { Heit } \\
2019\end{array}$ & $\begin{array}{l}\text { sur } \\
2019\end{array}$ & $\begin{array}{c}\text { 却 } \\
2015\end{array}$ & $\begin{array}{l}\mathrm{Ags} \\
2019\end{array}$ & $\left|\begin{array}{c}\operatorname{sen} \\
2010\end{array}\right|$ & $\begin{array}{c}0 k \mathrm{kt} \\
2019\end{array}$ & 2001 & $\begin{array}{c}\text { oes } \\
\text { zots }\end{array}$ & $\begin{array}{l}\operatorname{lan} \\
2020\end{array}$ \\
\hline 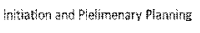 & $\times$ & $x$ & * & & & & & & & & & \\
\hline Dashboard Desigts & & * & * & * & $x$ & & & & & & & \\
\hline 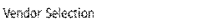 & & & & & $x$ & * & & & & & & \\
\hline Deyoumement and inglementation & & & & & & $\times$ & $x$ & $x$ & $x$ & & & \\
\hline Testity ant ato-live & & & & & & & & & & ${ }^{*}$ & $*$ & $x$ \\
\hline
\end{tabular}

Figure 6: Timetable for Dashboard

6) Why

In this case, the vision and mission of the university must be stated, namely: (1) vision: universities must provide quality in terms of learning, research and community service, and have a breakthrough in the 
development of existing knowledge, (2) mission: contribute to the community through education.

From the perspective of the business model, this explains the university's goal of wanting to achieve something supported by the existence of an information system as seen in the figure 7, including:

a) To see current business developments.

b) To anticipate problems that occur quickly and precisely.

c) To be able to see the potential that stands out at the university as a reference focus on university development and business strategy development.

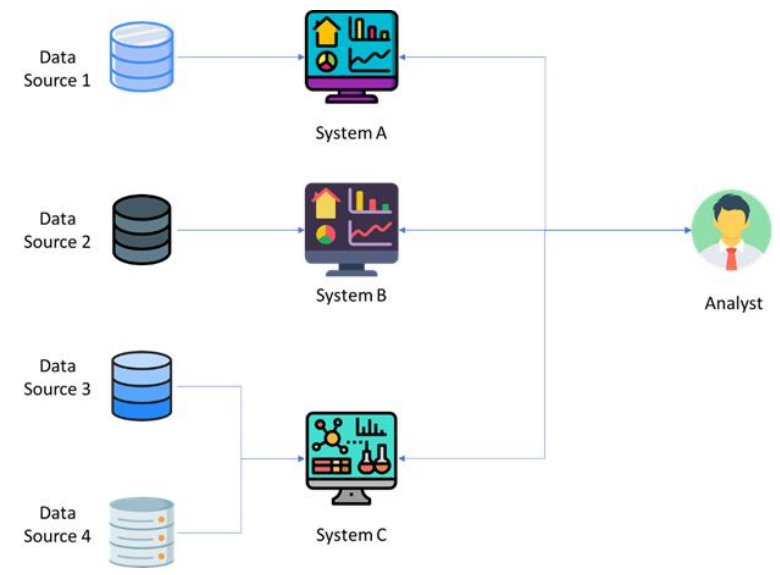

Figure 7: Information Systems Architecture

B. Acting

Alternative Determination:

Some alternatives that can be proposed are:

- By providing business intelligence applications to be able to find a deeper knowledge of data quickly.

- Make a dashboard that visualizes the achievement of targets and seen from all perspectives and dimensions, in the form of diagrams, tables.

Although the data comes from a variety of structures, with the use of Big Data this can be possible, the data can be viewed in real-time according to the university's development in terms of marketing and academics.

\section{Observing}

Alternative Determination:

Because this information will be seen and used by the leadership, the right alternative is to create a dashboard with the command center concept, and it must be accessible anywhere and anytime.

\section{Reflecting}

Implementation and Supervision:

The implementation plan starts with initial initiation and planning, then goes into making the dashboard design, if it uses vendor services then it continues with the selection of the right vendor to hold the project, after which it develops and implements, ends with testing and implementation.

EA's approach, in this case, supports the decision-making process, because EA focuses on the use of strategies from technology for good corporate information management and increases consistency, accuracy, timeliness, integrity, quality, availability, access, and sharing information management information technology in the company. Meanwhile, if you use IT architecture, the approach does not look at business processes where this development should pay attention to the strategic and business interests as well, because the EA approach can be modeled in terms of information systems and technology.

\section{CONCLUSION}

From the discussion that has been presented above, the researcher can draw some conclusions as seen in the figure 8 , the dashboard created will facilitate the leadership to analyze the university's development in terms of marketing and academics and current problems, and is also expected to be able to predict future problems. Thus the leadership can make program strategies more quickly and precisely. The visualization of data trends in terms of marketing and academics can measure the effectiveness of activities carried out in addition to making decisions made by the leadership can minimize errors made because it uses updated data and looks directly at data trends. The researcher's suggestion for the next development is also made a predictive and analytic prescriptive to answer what is happening, what will happen, and what action is most appropriate to take, so that big analytic data is truly reliable in making decisions by leaders.

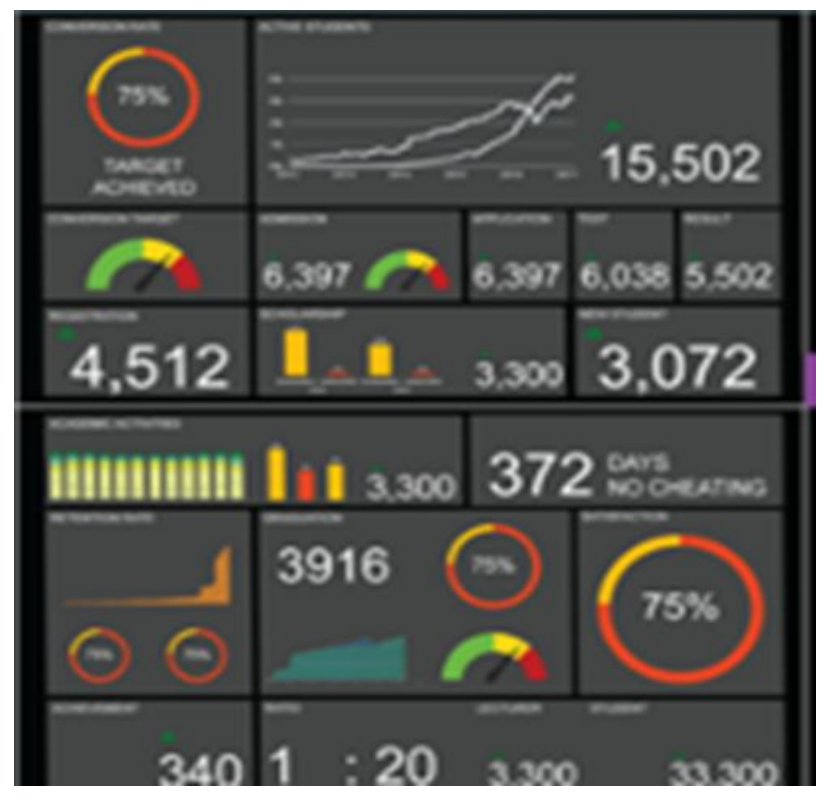

Figure 8: Dashboard Sample 


\section{REFERENCES}

1. Z. Khan and T. Vorley, "Big data text analytics: an enabler of knowledge management," J. Knowl. Manag., vol. 21, no. 1, pp. 18-34, 2017, doi: 10.1108/JKM-06-2015-0238.

2. Gunawan Wang, Lazuardi Ridho Maulana, Nico Leonardi, Emil Robert Kaburuan, "The Use of Big Data in Supporting Customer Profiling", International Journal of Advanced Trends in Computer Science and Engineering, Volume 9 No.2, March -April 2020, https://doi.org/10.30534/ijatcse/2020/35922020

3. Neha Jain, Yogesh Awasthi, "WSN-AI based Cloud Computing Architectures for Energy Efficient Climate Smart Agriculture with Big Data analysis", International Journal of Advanced Trends in Computer Science and Engineering, Volume 8, No.1.2, 2019, https://doi.org/10.30534/ijatcse/2019/1581.22019.

4. Lasimin, Kusrini, and E. T. Lutfi, "Enterprise Architecture Planning Manajemen Kampus Di Stikesal-Irsyad Al-Islamiyyah Cilacap,” J. Penelit. dan Pengabdi. Kpd. Masy. UNSIQ, no. 3, pp. 219-228, 2016.

5. G. F. Simons, L. A. Kappelman, J. A. Zachman, G. F. Simons, and D. Ph, "Complex Systems Design \& Management,” Complex Syst. Des. Manag., no. January, 2010, doi: 10.1007/978-3-642-15654-0.

6. J. Danny, Shanlunt, G. Wang, and H. Alianto, "The Application of Zachman Framework in Improving Better Decision Making," 1st 2018 Indones. Assoc. Pattern Recognit. Int. Conf. Ina. 2018 - Proc., pp. 245-249, 2019, doi: 10.1109/INAPR.2018.8627041. 